\title{
Effect of ozonation of swimming pool water on formation of volatile disinfection by- products - A laboratory study
}

Hansen, Kamilla Marie Speht; Spiliotopoulou, Aikaterini; Cheema, Waqas Akram; Andersen, Henrik Rasmus

Published in:

Chemical Engineering Journal

Link to article, DOI:

10.1016/j.cej.2015.12.052

Publication date:

2016

Document Version

Peer reviewed version

Link back to DTU Orbit

Citation (APA):

Hansen, K. M. S., Spiliotopoulou, A., Cheema, W. A., \& Andersen, H. R. (2016). Effect of ozonation of swimming pool water on formation of volatile disinfection by-products - A laboratory study. Chemical Engineering Journal, 289, 277-285. https://doi.org/10.1016/j.cej.2015.12.052

\section{General rights}

Copyright and moral rights for the publications made accessible in the public portal are retained by the authors and/or other copyright owners and it is a condition of accessing publications that users recognise and abide by the legal requirements associated with these rights.

- Users may download and print one copy of any publication from the public portal for the purpose of private study or research.

- You may not further distribute the material or use it for any profit-making activity or commercial gain

- You may freely distribute the URL identifying the publication in the public portal 


\title{
Effect of ozonation of swimming pool water on formation of volatile disinfection by-products - A laboratory study
}

\author{
Kamilla M. S. Hansen ${ }^{1}$, Aikaterini Spiliotopoulou ${ }^{2}$, Waqas Akram Cheema ${ }^{1,3}$, Henrik R. Andersen ${ }^{1 *}$ \\ ${ }^{1}$ Department of Environmental Engineering, Technical University of Denmark, Miljøvej 113, 2800 Kongens Lyngby, Denmark. *Corresponding \\ author: Henrik@ndersen.net \\ ${ }^{2}$ Water ApS, Farum Gydevej 64, 3520 Farum, Denmark. \\ ${ }^{3}$ National University of Sciences and Technology, H-12, Islamabad 44000, Pakistan.
}

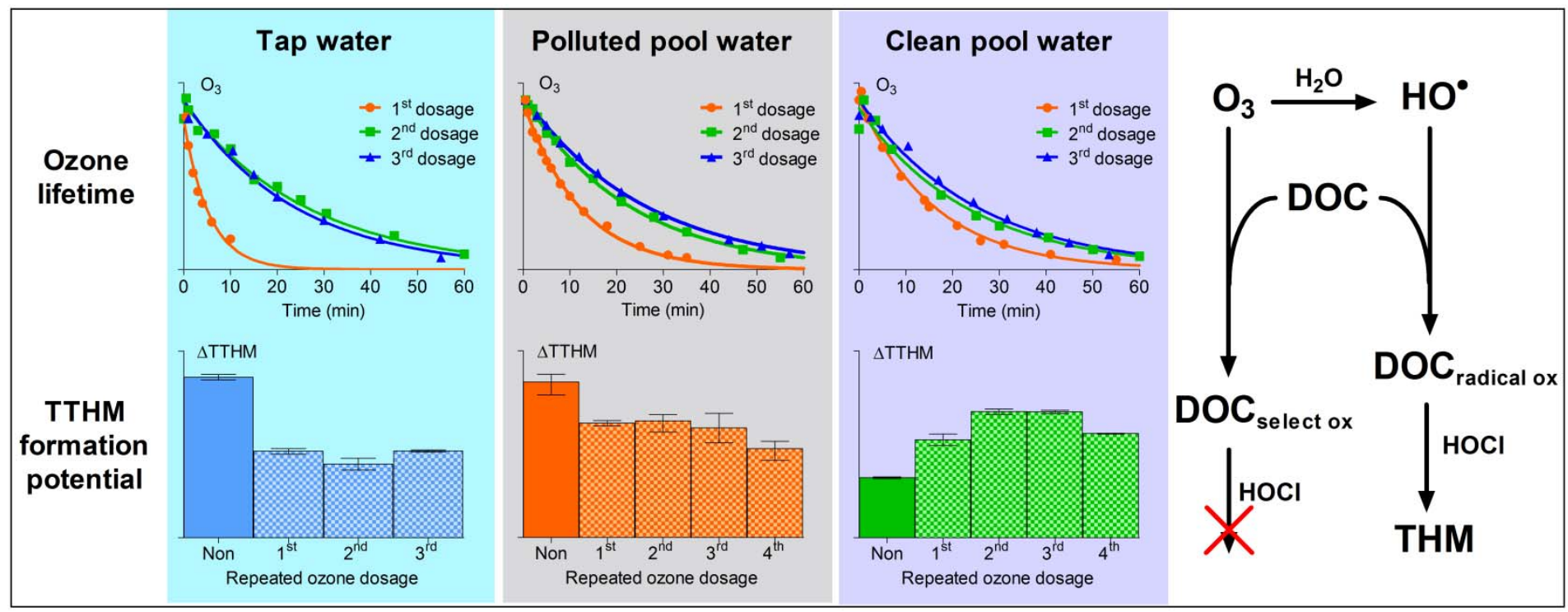

\begin{abstract}
Ozonation experiments were performed using unchlorinated tap water used for filling municipal swimming pools, actual pool water and pool water polluted by addition of fresh tap water and artificial body fluid to evaluate ozone kinetics and water quality effects on formation of volatile disinfection byproducts during subsequent chlorination.

The ozone reaction was observed to behave according to first order kinetics. For tap water half-life was 4 min whilst polluted and unpolluted pool water exhibited half-life of 8 and $11 \mathrm{~min}$, respectively. When ozonation dosage was repeated half-life of ozone was approximated 17-19 min in all samples.

Subsequent chlorination revealed ozone removed reactivity of dissolved organic carbon toward chlorine for tap and polluted pool water, decreasing formation rate of trihalomethanes (TTHM). In pool water higher rates of TTHM formation was observed after the initial ozone dosage, however this decreased with subsequent treatments. For tap and polluted pool water, ozone reacted directly with the pollutants resulting in a short ozone half-life, removing reactivity towards chlorine oxidation and preventing TTHM production. Conversely for pool water samples, due to the long half-life of ozone, the molecule decomposed to hydroxyl radicals. These in turn reacted with aqueous organic matter increasing chlorine reactivity and rates of TTHM formation. Formation of other non-regulated volatile byproducts (e.g. dichloracetonitrile, trichlorpropanone and trichloronitromethane) was observed to increase in pool water with ozone treatment. Thus, ozonation dosage regimes should be designed such that ozone mostly oxidizes fresh pollutants before chlorine is able to react with it.
\end{abstract}

Key-words: Ozone, swimming pool, trihalomethane, chlorination, ozonation, disinfection byproducts. 


\section{Introduction}

Chlorine is the most common disinfectant used in public swimming pools. However, chlorine reacts with natural organic matter present in the filling water and pollutants introduced into pool water by bathers forming disinfection by-products (DBPs $\left.{ }^{1}\right)$. The most common DBPs identified in pool water are combined chlorine species (organic and inorganic chloramines), haloacetic acids (HAAs), and trihalomethanes (THMs) $[1,2]$. The general concern regarding formation of DBPs is their effect on human health since some are genotoxic and thus might be carcinogenic [3]. The main removal mechanisms of the dissolved organic pollutants are oxidation by chlorine and subsequent mineralization.

Ozone is a strong oxidizing agent, with a great variation in reaction times depending on pollutants characteristics. When applied to swimming pool water ozone can oxidize dissolved pollutants (i.e. Dissolved organic carbon, DOC; Eq. 1) which reduces its reactivity with chlorine as both ozone and chlorine are selective oxidants that preferably react with the same parts of organic molecules. As chlorine reactivity of DOC decreases it can be expected that formation of DBPs decreases [4] in pool water following oxidation with ozone.

$$
\begin{array}{ll}
\mathrm{DOC}+\mathrm{O}_{3} \rightarrow \mathrm{DOC}_{\text {selectively oxidized }} & \text { Eq. } 1 \\
\mathrm{H}_{2} \mathrm{O}+\mathrm{O}_{3} \rightarrow \mathrm{O}_{2}+2 \mathrm{HO}^{\circ} & \left(\mathrm{HO}^{-} \text {catalyzed, slow at neutral } \mathrm{pH}\right) \\
\mathrm{DOC}+\mathrm{HO} \rightarrow \text { DOC }_{\text {radical oxidized }} & \text { Eq. } 2 \\
\text { Eq. } 3
\end{array}
$$

If ozone is not consumed quickly by reaction with reducing matter it will decompose to hydroxyl radicals (Eq. 2) in a competing reaction which rate increases with increasing $\mathrm{pH}[5,6]$. Hydroxyl radicals are nonselective, highly reactive species and thus can oxidize a range of dissolved pollutants (Eq. 3). Thus, the lifetime of ozone in water depends on $\mathrm{pH}$, DOC concentration, and the quality and functional groups of the DOC. Reaction of organic matter with hydroxyl radicals appears to increase the reactivity towards chlorine and formation of DBPs during chlorination [4,7] properly through introduction of more oxygen containing functional groups and breaking of carbon chains to leave more end-carbons available for oxidation.

Generally, most ozonation treatment of swimming pools is undertaken according to the German DIN standard where all or a part of the water is ozonated with a contact time of 3-10 min before destruction of ozone in an activated carbon filter. Destruction of ozone is performed in order to prevent ozone escaping to the air above the swimming pool, however this results in only a small part of the ozone dosage reacting with the treatment targets whilst the main mass of ozone is destroyed [8]. A radically different treatment principle, developed in the USA, is the slip-stream ozonation method which applies a low dose of ozone into a side stream of the filter flow. The low dose of ozone is consumed rapidly by reaction with organic in the main recirculation flow. The ozone dosing is controlled by a redox probe to ensure ozone is not added in excess of the dissolved organic matter present thereby ensuring ozone does not reach the pool. A third treatment principle is the ozone/bromide system where pool water containing bromide is ozonated to oxidize bromide to hypobromous acid, which then acts as a disinfectant [9]. Due to the high concentration of bromide in such systems, ozone is quickly consumed and no bromate is formed [10].

Literature concerning the effects of ozone on DBP formation in swimming pool water is limited. However, general knowledge regarding ozone and reactivity can be found in the literature particularly regarding ozonation of drinking water and wastewater, e.g. von Gunten [11]. For such applications it is seen that the most common DBPs, i.e. THM and HAA, react very slowly with ozone. Furthermore ozone's reaction with nitrogen compounds and chloramine is also relatively slow [8]. However, in a field application of ozone treatment of swimming pool water according to the DIN standard, a 34-48\% decrease in chloroform formation potential was achieved depending on ozone contact time [12]. Conversely in a laboratory batch experiment, Glauner et al. [4] obtained only a $12 \%$ reduction of absorbable organohalogen (AOX) formation potential and 3\% reduction in total trihalomethane (TTHM) formation potential after 10 min oxidation by ozone. In a Korean study, ozone/chlorine treated swimming pools had lower levels of DBPs than chlorinated

\footnotetext{
${ }^{1}$ Abbreviations applied in this manuscript:

AOX = Absorbable Organic Carbon

DBP = Disinfection by-product

DPD = N,N-Diethyl-p-phenylenediamine

DIN = Deutsches Institut für Normung

DOC= Dissolved organic carbon

HAA = Haloacetic acid

HAN = Haloacetonitrile

LOQ = Limit of quantification

NOM = Natural organic matter

THM = Trihalomethane

TTHM = Total Trihalomethane
} 
pools [13]. Whilst another study conducted in Canada found no difference on the chloramine level in a pool and spa with chlorine disinfection compared to a pool and a spa with ozone/chlorine treatment [14].

An increased understanding of ozonation in swimming pools (e.g. kinetics of reactions) could help in designing and implementing a more cost effective ozone treatment system and thereby minimize the occurrence of disinfection by-products in swimming pools. Thus, the aim of this current study is to determine the kinetics of ozone consumption with time in pool water and investigate the effect of ozonation on DBP formation. Ozonation experiments were performed to evaluate ozone kinetics and water quality effects on formation of volatile disinfection byproducts during subsequent chlorination. Ozonation was performed on actual pool water collected in a period when bathing attendance was low, in pool water polluted by addition of fresh tap water and artificial body fluids and on unchlorinated tap water used for filling municipal swimming pools. The two pool water illustrate the difference between fresh pollution in the pool and organic matter residuals from long chlorine exposure, while the tap water serves as a general reference to water ozonation.

\section{Material and methods}

\subsection{Reagents}

All reagents and chemicals were purchased at Sigma-Aldrich (Denmark) and used as received. The experimental set-up for ozonation was based on a $20 \mathrm{~g} / \mathrm{h}$ ozone generator from O3-Technology $\mathrm{AB}$ (Vellinge, Sweden) which was supplied with dry oxygen gas. Generated ozone was dispersed through a diffuser in a collection bottle containing ultra-pure water, which was immersed in an ice bath so that ozone solubility was maximized. To further increase solubility of ozone, a manometer and valve were placed after the collection bottle and a pressure at 1.4 barG was applied. Based on these experimental conditions, the concentration of ozone achieved in the stock solution was between 80 and $100 \mathrm{mg} / \mathrm{L}$.

\subsection{Water samples}

\subsubsection{Tap water}

The tap water stems from the public distribution network, which is comprised of non-chlorinated ground water.

2.2.2 Clean pool water

Pool water was collected from a public swimming pool and used for experiments on the day of collection. The pool for water collection was the main practice basin in Lyngby which is a typical public pool (temperature $27^{\circ} \mathrm{C}$, sand filter with flocculation, and a side stream activated carbon filter) with a hydraulic retention time (HRT) of $4 \mathrm{~h}$. Filling water for the swimming pool is obtained from the public distribution network, which is comprised of non-chlorinated ground water. Water samples were collected in the morning but during regular operating hours.

\subsubsection{Polluted pool water}

In order to simulate pollution for chlorine to react with, pool water was mixed with tap water (20\%) and spiked with an artificial body fluid analog made according to the recipe published by Judd and Bullock [15] consisting of the main components of sweat and urine. The addition of artificial body fluids increased the DOC concentration of $1.3 \mathrm{mg}-\mathrm{DOC} / \mathrm{L}$.

\subsection{Quantification}

\subsubsection{Ozone}

Ozone concentration was quantified by the indigo method [16]. Reagents used were $0.5 \mathrm{M}$ phosphate buffer at $\mathrm{pH} 2$ and $1.00 \mathrm{~g} / \mathrm{L}$ potassium indigotrisulfonate dissolved in $20 \mathrm{mM}$ phosphoric acid. For the ozone decomposition profile, the volumes from Bader and Hoigné [16] were downscaled to fit into a $3 \mathrm{~mL}$ cuvette. Specifically, $0.100 \mathrm{~mL}$ potassium indigotrisulfonate $(1.0 \mathrm{~g} / \mathrm{L})$ and $0.250 \mathrm{~mL}$ phosphate buffer $(0.5 \mathrm{M}$ at $\mathrm{pH}$ 2 ) were added to the cuvette. Next ultra-pure water and sample were added making a total volume of $2.5 \mathrm{~mL}$. The amount of sample and ultra-pure water were varied depending on ozone concentration. The absorbance of the unreacted indigotrisulphonate was measured at $600 \mathrm{~nm}$. Ozone concentrations were determined by a comparison of the absorbance of a blank and sample and using $\Delta \mathrm{A}=-200001 /(\mathrm{cm} \cdot \mathrm{mol}$ ozone added per $\mathrm{L})$.

\subsubsection{Dissolved organic Carbon (DOC)}

A Shimadzu ASI-V UVC/Persulphate analyzer was utilized for quantification of the non-volatile organic carbon in samples. Sample injection volume was $3.00 \mathrm{~mL}$ and a calibration curve was formed using potassium hydrogen phthalate standards with concentrations ranging from $50-2000 \mu \mathrm{g} / \mathrm{L}\left(\mathrm{R}^{2}=0.9994\right)$. The method quantification limit is $50 \mu \mathrm{g} / \mathrm{L}$. Hence forth non-volatile organic carbon results will be referred to as dissolved organic carbon (DOC). 


\subsubsection{Chlorine}

The concentration of chlorine and combined chlorine in swimming pool water samples were quantified upon arrival at the laboratory using a DPD based test kit (LCK 310, Hach Lange, Denmark). The concentration of chlorine during experiments was quantified using the ABTS method [17] which results in induction of a green color in samples which is quantified by reading the absorption at $405 \mathrm{~nm}$.

\subsubsection{Volatile DBP}

Analyses were performed as previously described by [18]. Samples were analyzed by purge and trap (purge temperature $=30{ }^{\circ} \mathrm{C}$, Velocity XPT Purge and Trap Sample Concentrator, Teledyne Tekmar, with autosampler: AQUATek 70, Teledyne Tekmar) coupled with a GC-MS (HP 6890 Series GC System, 5973 Mass selective detector, Hewlett Packard). The method employed detects for the following compounds: chloroform, bromodichloromethane, dibromochloromethane, bromoform, dichloroacetonitrile, bromochloroacetonitrile, dibromoacetonitrile, trichloroacetonitrile, trichloropropanone, dichloropropanone, and trichloronitromethane. The limit of quantification (LOQ) is based on the lowest standard of the linear calibration curve and was found to be $0.6 \mu \mathrm{g} / \mathrm{L}$ for THMs and dichloroacetonitrile and $1.0 \mu \mathrm{g} / \mathrm{L}$ for dichloropropanone, trichloropropanone, trichloroacetonitrile, bromochloroacetonitrile, dibromoacetonitrile and trichloronitromethane.

\subsection{Treatment}

\subsubsection{Ozonation}

Ozonation of water samples was achieved by adding an amount of ozone stock solution (i.g. $3 \mathrm{~mL}$ ) to a water sample $(100 \mathrm{~mL})$. The ozone dose was then determined by adding a sufficient amount of potassium indigotrisulfonate and $10 \mathrm{~mL}$ phosphate buffer into a separate $100 \mathrm{~mL}$ total volume solution and measuring absorbance for comparison. For example, if a water sample (i.e. $100 \mathrm{~mL}$ ) was ozonated with an ozone dose of $2 \mathrm{mg} / \mathrm{L}$ the applied ozone dosage was determined by adding $4.0 \mathrm{~mL}$ indigotrisulphonate $(1.0 \mathrm{~g} / \mathrm{L})$ and 10 $\mathrm{mL}$ phosphate buffer in a $100 \mathrm{~mL}$ volumetric flask, filling to capacity with ultra-pure water and then pouring into a glass bottle. The same amount of ozone stock solution was then added to the glass bottle as added to the water sample. The absorbance of the unreacted indigotrisulphonate was measured at $600 \mathrm{~nm}$ and compared to the absorbance of a blank. The ozone dose was then determined using $\Delta \mathrm{A}=-200001 /(\mathrm{cm} \cdot \mathrm{mol}$ ozone added per L).

\subsubsection{Chlorination}

In the current study the formation of DBPs from chlorination was investigated using a standardized DBP formation assay. Similar tests have been used in other studies that investigate the potential for the formation of $\mathrm{NCl}_{3}$ [19], THM and HAA in swimming pool water [20], THM, HAN and HAA from synthetic body fluid [21] and particles from pools [22]. The effect of chlorine concentration in the assay was also recently investigated by Hansen et al. [23]. In a more recent paper, the chlorination assay was used to simulate reaction with chlorine when UV treated water was returned to the pool [7]. In this current study the same approach is used to simulated chlorination in the pool after the return of ozone treated water.

After ozonation, water samples were transferred to $40 \mathrm{~mL}$ glass vials where chlorine and boric acid were added based on the chlorine consumption determined in pre-experimental tests. The aim was to have 1-3 mg $\mathrm{Cl}_{2} / \mathrm{L}$ after $24 \mathrm{~h}$ at $25^{\circ} \mathrm{C}$ (measured by ABTS). The chlorination was performed in quintuplicates with three samples used for DBP analysis and two for the determination of residual chlorine. Samples for DBP analyses were also dosed with ammonium chloride solution $(50 \mathrm{mg} / \mathrm{L})$ to quench free chlorine which does neither affect the already formed DBP [24] nor increase the N-DBP formation [25]. The samples were analyzed the same day.

\subsection{Experiments}

\subsubsection{Effect of $\mathrm{pH}$}

A swimming pool water sample was divided into 4 subsamples and $\mathrm{pH}$ adjusted to 6.8, 7.0, 7.3, and 7.8 with $\mathrm{NaOH}$ or $\mathrm{HCl}$ respectively. Subsamples were then placed in a water bath with controlled temperature $\left(28^{\circ} \mathrm{C}\right)$ and ozonated with approximately $2.3 \mathrm{mg} / \mathrm{L}$ by adding ozone stock solution. Ozone concentration was then monitored with time to follow consumption in the sample.

\subsubsection{Repeated ozonation of pool water}

A swimming pool water sample was divided into 5 subsamples $(300 \mathrm{~mL}$ each) and placed in a water bath with controlled temperature $\left(28{ }^{\circ} \mathrm{C}\right)$. Four of the subsamples were ozonated with $2 \mathrm{mg} / \mathrm{L}$ ozone $\left(1^{\text {st }}\right.$ ozone dosage). Ozone dosage was determined as previously described in section 2.3.1. In one of the subsamples ozone concentration was measured over time. When the ozone dosage was determined to be depleted, a further dosage was applied $\left(2 \mathrm{mg} / \mathrm{L} ; 2^{\text {nd }}\right.$ ozone dosage); however only for the remaining three samples. 
Subsequently, the ozone concentration was monitored with time in one of the samples. A $3^{\text {rd }}$ ozone dosage ( 2 $\left.\mathrm{mg}-\mathrm{O}_{3} / \mathrm{l}\right)$ was applied for the remaining two subsamples. Again the ozone concentration was followed until depletion and a $4^{\text {th }}$ ozone dosage $\left(2 \mathrm{mg}-\mathrm{O}_{3} / \mathrm{L}\right)$ was added to the last remaining subsample. The samples used for ozone profiles and the non-ozonated sample were subsequently chlorinated as described in Section 2.3.2 follow by DBP analysis (Section 2.2.4).

\subsubsection{Polluted pool water}

The polluted pool water was divided into subsamples which were ozonated with different doses ranging from $0.7 \mathrm{mg} / \mathrm{L}$ to $3.4 \mathrm{mg} / \mathrm{L}$. A sample simulating extended ozonation was produced by replacing the ultra-pure water in the collection bottle used to produce the ozone stock solution (see section 2.1) with polluted pool water and ozonating the sample for $30 \mathrm{~min}$ at approximately $100 \mathrm{mg} \mathrm{O} / \mathrm{L}$. This was done to simulate pool water being recirculated for months in the pool and thus repeatedly ozonated giving effectively a very high ozone exposure. Samples were placed at $28{ }^{\circ} \mathrm{C}$ for 12 hours to ensure no ozone residual before chlorination according to Section 2.3.2 follow by DBP analysis (Section 2.2.4). DOC was measured before and after ozonation.

\section{Results and discussion}

Several European countries (for example Denmark and Germany) have included in their swimming pool water regulation limit for THMs. Additionally, it has been discussed in the drinking water regulation to include HAN limitation as they are more genotoxic than THM. Thus, THM and HAN are analyzed in swimming pool water with an analytical method including dichloropropanone, trichloropropanone and trichloronitromethane. Thereby, eleven DBPs, which are usually found in swimming pool water [1], were examined. However, bromochloroacetonitrile, dibromoacetonitrile, trichloroacetonitrile and trichloronitromethane were not detected and are consequently omitted in the following discussion.

\subsection{Kinetic of ozone reaction}

\subsection{1 $\mathrm{pH}$}

To evaluate the effect of $\mathrm{pH}$ on decomposition of ozone in a $\mathrm{pH}$ range relevant for swimming pools, four subsamples from a swimming pool were adjusted to different $\mathrm{pH}$ values and ozonated. The profiles of the ozone concentration over time are shown in Figure 1a. As seen, decomposition of ozone did not vary in the investigated range. Half-life time of 10-12 min was estimated at all $\mathrm{pH}$ levels based on fitting a first order kinetic equation to the measured ozone concentrations. According to Rice [26] the expected half-life time of ozone in swimming pool water should be approximately $10 \mathrm{~min}$, which fits well with our findings.

\subsubsection{Effect of matrix}

Ozonation experiments were performed for three kinds of water i.e. tap water (DOC $=2.0 \mathrm{mg} / \mathrm{L}$ ), clean pool water $(\mathrm{DOC}=1.5 \mathrm{mg} / \mathrm{L})$ and simulated polluted pool water $(\mathrm{DOC}=2.4 \mathrm{mg} / \mathrm{L})$. Concentration of ozone in the tap water (Figure 1b) decreased faster $\left(t_{1 / 2}=3.8 \mathrm{~min}\right.$ ) at the first ozone dosage than at the second and third ozone doses $\left(t_{1 / 2,2 n d}=19 \mathrm{~min}\right.$ and $\left.t_{1 / 2,3 r d}=17 \mathrm{~min}\right)$. Thus, the first ozone dose reacted with the part of the DOC which has high reactivity towards ozone while at second and third dose the ozone reacted with more recalcitrant parts of DOC or decomposed to hydroxyl radicals. Decomposition of ozone in ultra-pure water was also tested and was found to be slower than in the second and third ozone dose in tap water. For pool water (Figure 1c), the first ozone dose reacted slower $\left(t_{1 / 2}=11 \mathrm{~min}\right)$ compared to tap water. However, the second dose dissipated more rapidly $\left(t_{1 / 2}=8 \mathrm{~min}\right)$. The likely cause of this was the long lifetime of the first ozone dose, inferring decomposition to hydroxyl radicals had taken place, consequently reacting with the DOC inducing greater reactivity towards ozonation during the second dose. The half-life of the third and fourth ozone dose $\left(\mathrm{t}_{1 / 2,3 \mathrm{rd}}=17 \mathrm{~min}, \mathrm{t}_{1 / 2,4 \mathrm{th}}=18 \mathrm{~min}\right)$ were similar to those $\left(2^{\text {nd }}\right.$ and $\left.3^{\text {rd }}\right)$ for the tap water. For polluted pool water (Figure 1d), the first ozone dose reacted more rapidly $\left(\mathrm{t}_{1 / 2}=8.4 \mathrm{~min}\right.$ ) than for pool water but slower than tap water. This is clearly a result of mixing pool water with tap water and BFA since tap water and BFA are non-chlorinated and likely to be more reactive towards ozone than the chlorinated pollutant in pool water. The half-life of the $2^{\text {nd }}$ and $3^{\text {rd }}$ ozone dose $\left(t_{1 / 2,2}{ }^{\text {nd }}=16 \mathrm{~min}\right.$ and $t_{1 / 2}$, 3rd $\left.=18 \mathrm{~min}\right)$ were quite similar to those for the ozonated tap water $\left(2^{\text {nd }}\right.$ and $\left.3^{\text {rd }}\right)$ and pool water $\left(3^{\text {rd }}\right.$ and $\left.4^{\text {th }}\right)$. Thus, the first ozone dose reacted with the DOC which has high reactivity towards ozone after which ozonation of the more recalcitrant DOC occurred. Alternatively or in addition, ozone decomposed to hydroxyl radicals (Eq. 2) which then reacted with the DOC (Eq. 3). 
(a) $\mathrm{pH}$ (Clean pool water)

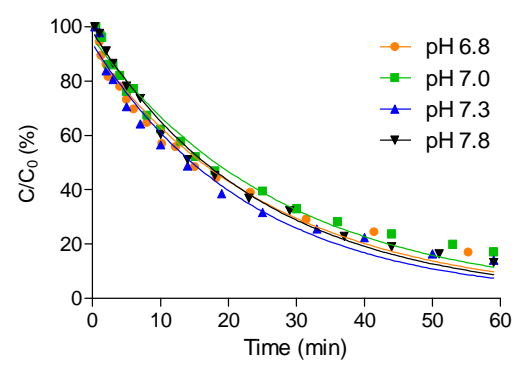

(c) Clean pool water

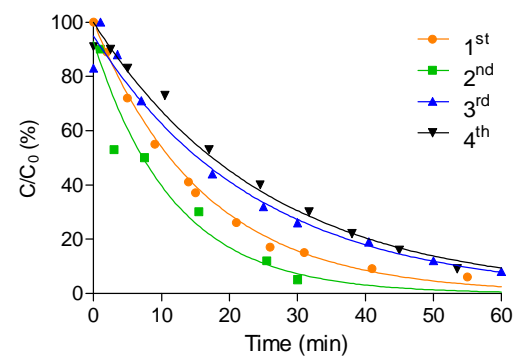

(b) Tap Water

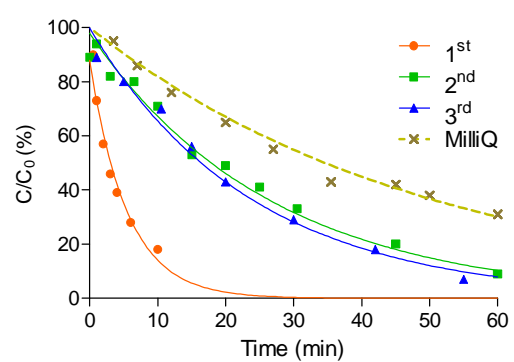

(d) Polluted pool water

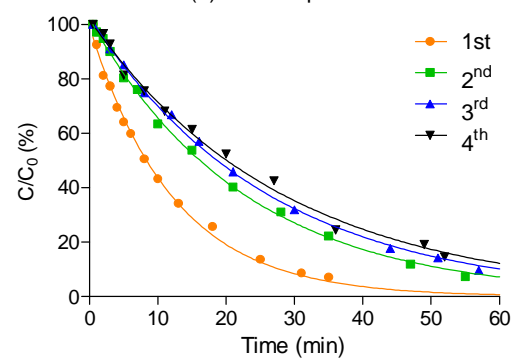

Figure 1. Concentration profile of ozone in a) swimming pool water at different $\mathrm{pH}(\mathrm{DOC}=2.3 \mathrm{mg} / \mathrm{L}) \mathrm{b})$ tap water $(\mathrm{pH}$ $=7.9, \mathrm{DOC}=2.0 \mathrm{mg} / \mathrm{L}$ ) and ultra-pure water (buffered at $\mathrm{pH} 7.3$ with phosphate), $\mathrm{c}$ ) swimming pool water $(\mathrm{pH}=7.3$, $\mathrm{DOC}=1.5 \mathrm{mg} / \mathrm{L})$, and d) mixture consisting of $80 \%$ pool water, $20 \%$ tap water and artificial body fluid $(\mathrm{pH}=7.3$, $\mathrm{DOC}=2.4 \mathrm{mg} / \mathrm{L}$ ). The water samples were treated repeatedly with ozone doses of approximately $2 \mathrm{mg} / \mathrm{L}$.

\subsection{Effect of ozone on water quality}

Changes in water quality were investigated through chlorine consumption and DOC analysis. For tap water and clean pool water the chlorine residual after $24 \mathrm{~h}$ at $25^{\circ} \mathrm{C}$ was $1.7 \pm 0.1 \mathrm{mg} / \mathrm{L}$, while for the polluted pool water it was $1.0 \pm 0.3 \mathrm{mg} / \mathrm{L}$. Chlorine consumption was calculated by subtracting the chlorine residual from the added chlorine dose. In tap water, chlorine consumption (Figure 2a) decreased with the first ozone dose and then slightly rebounded with repeated ozonation. This is consistent with the concept that the first ozone dose mainly reacts by direct oxidation of ozone with functional groups in the DOC and thus oxidized the functional groups of NOM which would otherwise react with chlorine as can be seen from the faster consumption of ozone as discussed in Section 3.1.2. Furthermore, for the second and third ozone dose the oxidation was mainly by hydroxyl radicals which are non-selective resulting in increased chlorine reactivity.

(a) Clorine Consumption

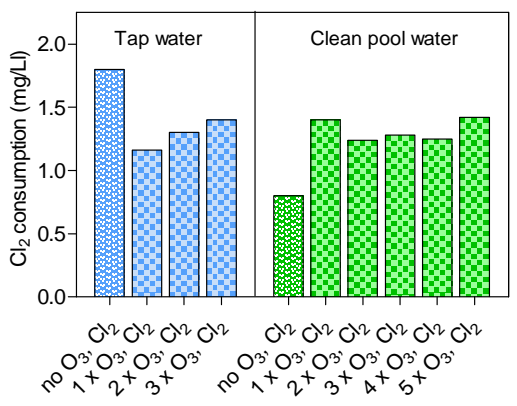

(b) Chlorine consumption

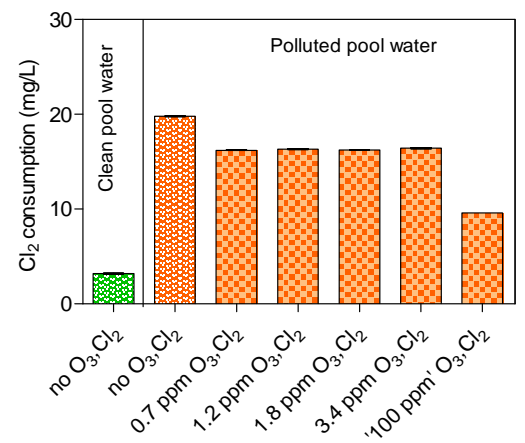

(c) Dissolved organic carbon

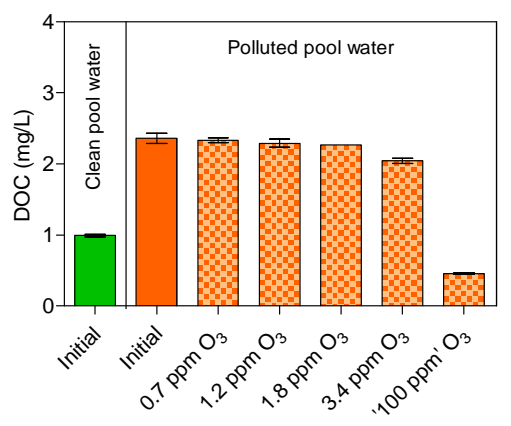

Figure 2. a) and b) Chlorine consumption (Temperature $=25^{\circ} \mathrm{C}, 24 \mathrm{~h}$ ) of tap and clean pool water, and polluted pool water; c) DOC level in clean pool water and polluted pool water.

For clean pool water, the non-ozonated sample had the lowest chlorine consumption while ozonation of the sample increased chlorine consumption. Repeated ozonation did not result in further increase of chlorine consumption but a steady level at approximately $1.3 \mathrm{mg} \mathrm{Cl} / 2$ was observed. The increase in chlorine reactivity could be explained by oxidation of DOC by hydroxyl radicals which is consistent with the relative long half-life of ozone observed in clean pool water (Figure 1c).

Chlorine consumption in polluted pool water was much higher than that observed for clean pool water samples (Figure $2 \mathrm{~b}$ ). This is due to the fact that pool water had been chlorinated for a significant time prior to 
the experiment, therefore most of the DOC has already been oxidized by chlorine. In contrast polluted pool water contained fresh organic matter (provided by the sample spike) which had not previously been chlorinated and therefore reacted rapidly with chlorine. Ozonation with low ozone dosage decreased chlorine consumption to a steady level (Figure $2 \mathrm{~b}$, no $\mathrm{O}_{3}, \mathrm{Cl}_{2}$ vs $0.7 \mathrm{ppm} \mathrm{O}_{3}, \mathrm{Cl}_{2} ; 1.2 \mathrm{ppm} \mathrm{O}_{3}, \mathrm{Cl}_{2} ; 1.8 \mathrm{ppm} \mathrm{O}_{3}, \mathrm{Cl}_{2}$ and $3.4 \mathrm{ppm} \mathrm{O}_{3}, \mathrm{Cl}_{2}$ ) while for the sample simulating extended ozonation ('100 ppm' $\mathrm{O}_{3}, \mathrm{Cl}_{2}$ ) chlorine consumption decreased further.

The addition of tap water and artificial body fluid to pool water to simulate pollution of the pool more than doubled the DOC level (Figure 2c). Subsequent ozonation with doses from 0.7 to $3.4 \mathrm{mg} \mathrm{O}_{3} / \mathrm{L}$ resulted in a minor decrease in DOC levels. However, compared to the initial DOC the changes are insignificant. Similar trend is expected to appear in the other water types. For the sample simulating extended ozonation (' 100 ppm' $\mathrm{O}_{3}, \mathrm{Cl}_{2}$ ), which were exposed to approximately $100 \mathrm{mg} / \mathrm{L}$ of ozone for $30 \mathrm{~min}$, the DOC level decreased to a fifth of the polluted pool water DOC which was even lower than in the initial pool water.

\subsection{Formation of disinfection by products}

\subsubsection{Tap water}

\subsubsection{Effect of ozone on formation of trihalomethanes}

The chlorination of tap water formed a considerable concentration of chloroform and as tap water contained a small amount of bromide, bromine containing THM's were also produced in notable concentrations (Figure 3). After addition of the first ozone dose $(2 \mathrm{mg} / \mathrm{L}$ of ozone) the formation of all THMs (Figure 3a-e) decreased. In addition, formation of chloroform was reduced to approximately one third of that observed following chlorination of tap water. However, with further ozone dosage formation of chloroform increased. The concentration of bromodichloromethane (Figure 3b) and dibromochloromethane (Figure 3c) reduced further with the addition of the second ozone dose, however, further ozone doses had little more effect. Bromoform was formed during chlorination of the non-ozonated sample and the sample treated with one ozone dose. However, for the sample repeatedly ozonated no formation of bromoform was observed during chlorination. With regards to TTHM, an almost 50\% decrease in the concentration formed after ozone treatment by the addition of the first ozone dose was observed. However, no further reduction was observed following subsequent doses most likely a result of the further decrease in bromine containing TTHMs being matched by increasing chloroform formation.

Mechanistically, this can be explained by assuming the NOM present in the tap water contained some functional groups which are reactive to chlorine and ozone. These functional groups react quickly with the first ozone dose as observed in the faster removal rate (Figure 1b). Subsequent doses of ozone did not have reactive functional groups to react with thus exhibited a longer half-life in the water, reacting with water to form hydroxyl radicals according to Eq. 2 which in turn leads to radical oxidation according to Eq 3. This mechanism may result in increased chlorine reactivity and THM formation as DOC with low chlorine reactivity may be oxidized by the hydroxyl radicals becoming more reactive towards chlorine. Equilibrium would be reached (according to Eq 1 and 3) which results in the reactivity of the water remaining essentially unchanged. This process is supported by the observation of almost unchanged chlorine consumption (Figure 2a), reaction time of ozone (Figure 1b) and TTHM formation potential (Figure 3e).

The decreasing fraction of bromine containing TTHMs formed after the second and third ozone treatments can also be explained by considering the half-life increase of ozone. This in turn induces a competing reaction involving oxidation of bromide to bromate to occur.

\subsubsection{Effect of ozone on formation of miscellaneous DBPs}

Dichloroacetonitrile and trichloropropanone were both detected in chlorinated tap water samples however at levels below the limit of quantification (Figure $3 \mathrm{e}$ and $3 \mathrm{f}$ ). After ozonation and chlorination, the levels remained below the limit of quantification therefore results will not be discussed further.

\subsubsection{Clean pool water}

\subsubsection{Effect of ozone on formation of trihalomethanes}

The effect of ozone treatment on swimming pool water was in contrast to that observed for tap water. For swimming pool water, mainly chloroform was detected together with a small amount of bromodichloromethane whilst concentrations of dibromochloromethane and bromoform were below the limit of quantification. After addition of the first and second ozone dose $(2 \mathrm{mg} / \mathrm{L}$ of ozone each) formation of chloroform increased compared to that observed for non-ozonated samples. Further addition of ozone decreased formation however it remained higher than observed in the non-ozonated samples. As the amount of bromine in pool water was low and considering bromine incorporation did not change during the experiments, TTHM followed the same pattern as chloroform. 
The increase in chloroform formation during initial ozone dosage is likely due to radical oxidation of DOC present in the pool water. As mentioned previously, DOC in the pool water has been in contact with chlorine for a significant time period prior to the experiment thus it reacts slowly with ozone (Figure 1c) and ozone is able to decompose to hydroxyl radicals. The decrease in chloroform formation following a fourth and fifth ozone dosage was likely due to that fraction of DOC becoming mineralized with increasing oxidation.

\subsubsection{Effect of ozone on formation of miscellaneous DBPs}

Dichloroacetonitrile was quantified following chlorination of clean pool water. Treating the sample with ozone was seen to increase concentration of dichloroacetonitrile. Increasing treatments (first to fifth ozone doses) were observed to further increase concentrations (Figure 3f).

Trichloropropanone was detected below the limit of quantification in the chlorinated pool water sample (Figure 3g). Similar to dichloroacetonitrile, ozone dosage increased the formation of trichloropropanone during subsequent chlorination, particularly after a fifth dosage (5 times $2 \mathrm{mg} \mathrm{O}_{3} / \mathrm{L}$ ).

Both dichloroacetonitrile and trichloropropanone are unlikely to be direct ozonation byproducts however ozonation likely produced precursors which during subsequent chlorination formed dichloroacetonitrile and trichloropropanone.
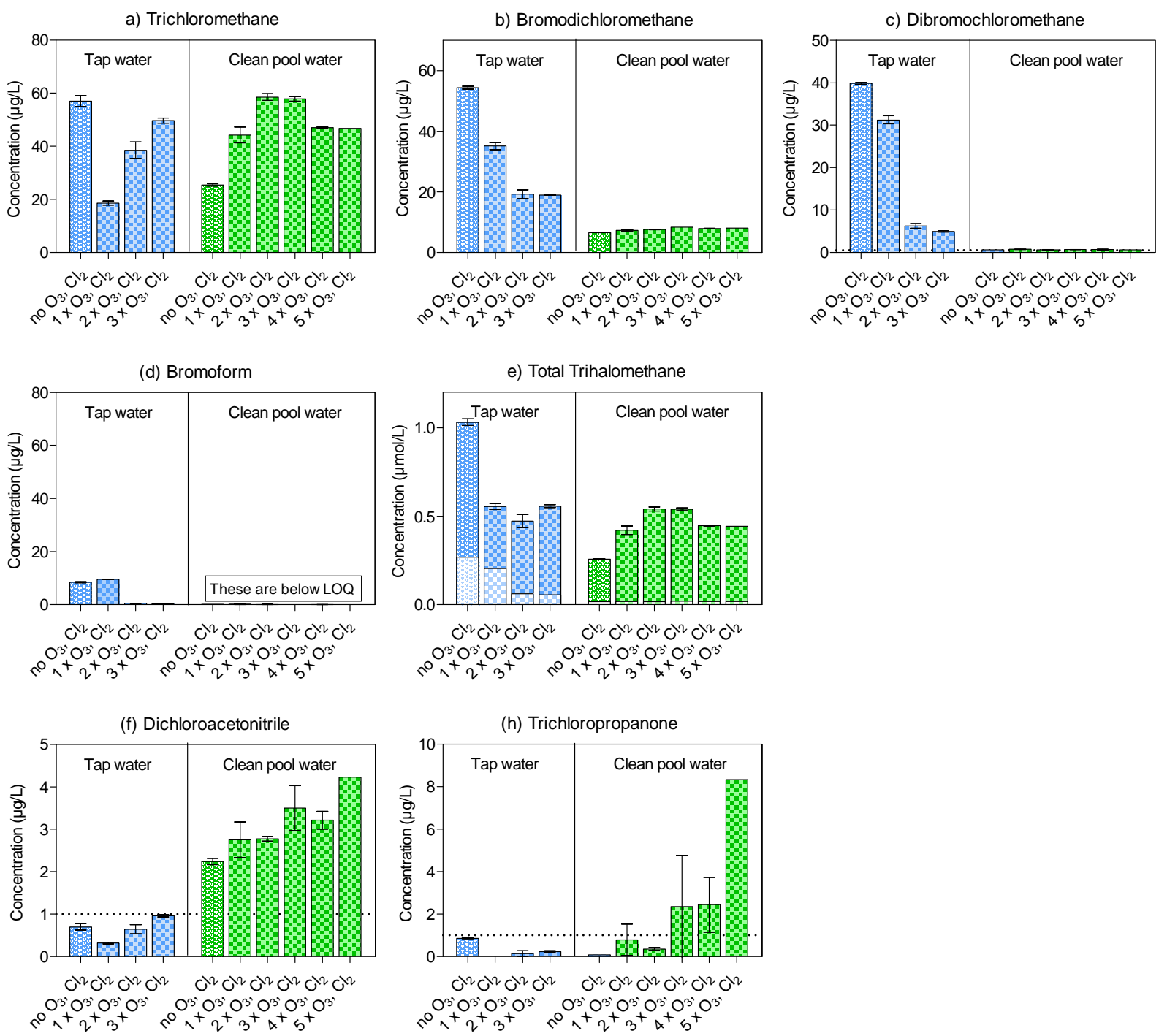

Figure 3. The concentration of DBPs formed by reaction with chlorine following repeated ozonation of tap and swimming pool water. The white parts on e) Total trihalomethanes indicates the amount of incorporated bromine. Error bars indicate the range of the results.

\subsubsection{Polluted pool water}

3.3.3.1 Effect of ozone on formation of trihalomethanes

Chlorination of polluted pool water resulted in elevated levels of chloroform, bromodichloromethane and dibromochloromethane compared to initial conditions (Figure 4). In contrast, the level of bromoform was below the limit of quantification in all cases and is therefore not shown in Figure 4. Addition of ozone 
decreased formation of chloroform during subsequent chlorination and increasing ozone dosage tended to decrease formation further. The sample simulating extended ozonation (' $100 \mathrm{ppm}$ ' $\mathrm{O}_{3}$ ) contained low concentration of chloroform which increased marginally during chlorination. The formation of bromodichloromethane (Figure $4 \mathrm{~b}$ ) and dibromochloromethane (Figure 4c) was not affected with ozone treatment in the range $0.7-3.4 \mathrm{mg} \mathrm{O} / \mathrm{L}$. However, in the sample simulating extended ozonation the concentration decreased to below the limit of quantification.

Variation in the formation of TTHM's followed the same pattern as chloroform since no change in formation bromodichloromethane and dibromochloromethane was observed. The sample simulating extended ozonation exhibited the lowest levels of TTHM formation likely due to mineralization of the main fraction of DOC (Figure 2c).

Mechanistically, this can be explained by ozone reacting with the functional groups of the spiked DOC (i.e. simulated sweat and urine), molecules which would otherwise react with chlorine and formed THM according to Eq. 1. The lack of change in bromine containing THM can also be explained by reaction of ozone with spiked DOC. This mechanism results in a relatively short half-life for ozone and thus no oxidation of bromide occurs. In the sample treated with high ozone dosage (simulating water being ozonated several times in a recirculation system) equilibrium between oxidation by radicals (making the DOC more chlorine reactive) and mineralization can explain low levels of THM formation even after extreme ozone exposure.
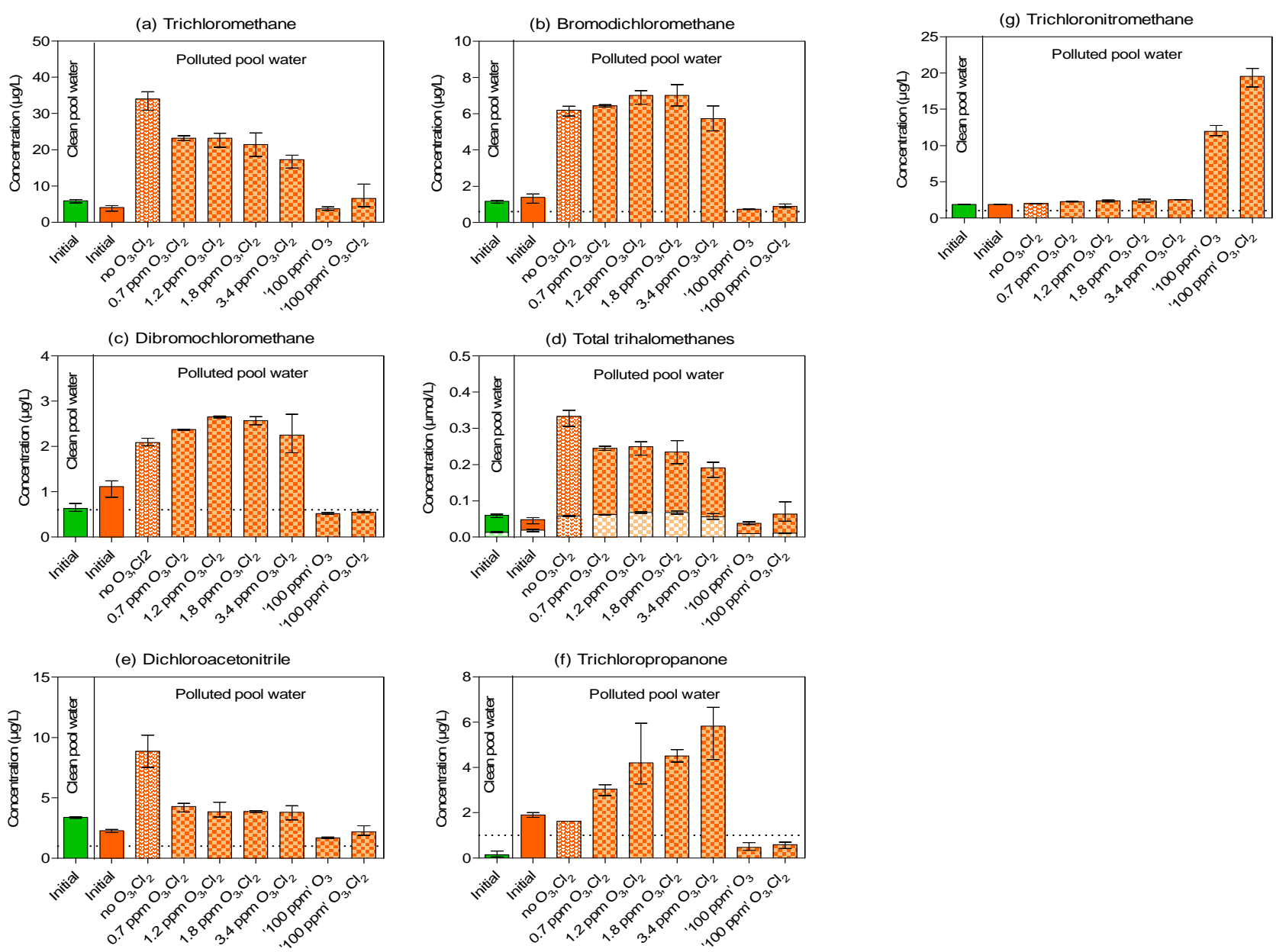

Figure 4. The formation of DBPs in polluted swimming pool water treated with different ozone doses The error bars indicates the range of the measured values.

\subsubsection{Effect of Ozone on formation of miscellaneous DBPs}

In the polluted swimming pool sample, low levels of dichloroacetonitrile, trichloropropanone and trichloronitromethane were observed following ozone dosage. Formation of dichloroacetonitrile decreased in the ozonated sample in comparison with the chlorinated sample. In the sample simulating extended ozonation, a further decrease was observed. For trichloropropanone, formation increased with increasing ozone dosage. However, in the sample simulating extended ozonation formation decreased with concentrations below the limit of quantification. Trichloronitromethane was detected at the same low level in the initial pool water sample, in chlorinated samples and in ozone treated samples with subsequent 
chlorination. Contrary to the other DBPs, trichloronitromethane increased in the sample simulating extended ozonation (' 100 ppm' $\mathrm{O}_{3}, \mathrm{Cl}_{2}$ ). Increased formation of trichloronitromethane by ozonation followed by chlorination is known in drinking water treatment [27,28]. Since elevated level of trichloronitromethane were also observed in the ozone dosage only samples (' $100 \mathrm{ppm}$ ' $\mathrm{O}_{3}$ ), trichloronitromethane can be identified as an ozonation byproduct.

\section{Conclusions}

Results of this study showed:

- Ozonation of tap water used to fill swimming pools and pool water with fresh non-chlorinated pollution reduced THM formation.

- Ozonation of pool water increased THM formation as ozone reacts slowly with recalcitrant organic matter that remains after extended chlorination. Consequently, ozone is degraded to hydroxyl radicals which then react with dissolved organic pollutants making them more reactive to subsequent chlorination.

- Repeated ozone dosage decreased the total organic matter concentration and the TTHM formation.

- Repeated ozone dosage decreased the fraction of TTHMs which are brominated, most likely as bromide is completely oxidized to bromate.

- Volatile DBPs such as dichloroacetonitrile, trichloropropanone and trichloronitromethane which are typically not regulated in swimming pools behave differently than THMs following ozonation and chlorination treatment. Thus, understanding this behavior and characterizing if these DBP's are mitigated or increased by swimming pool ozonation requires further detailed investigation in a real pool setting. Through such a study it should be possible to understand the dynamics between induction and degradation by further reaction with ozone.

Thus, during design of an ozonation process for treating pool water, it is imperative that ozone is able to react rapidly with DOC present and not remain in solution allowing chlorine to react with it.

\section{Acknowledgement}

The authors wish to thank Professor D. Eichelsdörfer (late) for suggesting this research and recognize his predictions of ozone behavior in pool water. Further we recognize Lyngby swimming pool staff for their cooperation and assistance in obtaining water samples.

\section{References}

[1] S. Chowdhury, K. Al-Hooshani, T. Karanfil, Disinfection Byproducts in Swimming Pool: Occurrences, Implications and Future Needs, Water Res. (2014). doi:10.1016/j.watres.2014.01.017.

[2] WHO, Guidelines for safe recreational water environments, World Health Organization, WHO Press, Geneva, Switzerland, 2006.

[3] S.D. Richardson, M.J. Plewa, E.D. Wagner, R. Schoeny, D.M. DeMarini, Occurrence, genotoxicity, and carcinogenicity of regulated and emerging disinfection by-products in drinking water: A review and roadmap for research, Mutat. Res. Mutat. Res. 636 (2007) 178-242. ISI:000251925500008.

[4] T. Glauner, F. Kunz, C. Zwiener, F.H. Frimmel, Elimination of swimming pool water disinfection byproducts with advanced oxidation processes (AOPs), Acta Hydrochim. Hydrobiol. 33 (2005) 585594.

[5] M.G. Antoniou, H.R. Andersen, Evaluation of pretreatments for inhibiting bromate formation during ozonation., Environ. Technol. 33 (2012) 1747-53. doi:10.1080/09593330.2011.644586.

[6] C. von Sonntag, U. von Gunten, Chemistry of Ozone in Water and Wastewater Treatment: From Basic Principles to Applications, 1st ed., IWA Publishing, 2012.

[7] A. Spiliotopoulou, K.M.S. Hansen, H.R. Andersen, Secondary formation of disinfection by-products by UV treatment of swimming pool water, Sci. Total Environ. 520 (2015) 96-105. doi:10.1016/j.scitotenv.2015.03.044.

[8] D. Eichelsdörfer, J. Jandik, Long contact time ozonation for swimming pool water treatment, Ozone Sci. Eng. 7 (1985) 93-106. doi:10.1080/01919518508552328.

[9] M. Hoffmann, Ozone-Bromine Treatment - Water Treatment in Public Pools without Chlorine - A new standard?, Ozone Sci. Eng. In press (2015) 150709012841000. doi:10.1080/01919512.2015.1053014.

[10] M. Bataller, E. Veliz, R. Pérez-Rey, L. a. Fernández, M. Gutierrez, a. Márquez, Ozone Swimming 
Pool Water Treatment Under Tropical Conditions, Ozone Sci. Eng. 22 (2000) 677-682. doi:10.1080/01919510009408806.

[11] U. von Gunten, Ozonation of drinking water: part I. Oxidation kinetics and product formation., Water Res. 37 (2003) 1443-67. doi:10.1016/S0043-1354(02)00457-8.

[12] D. Eichelsdörfer, J. Jandik, Application of ozone for treatment of swimming pool water in the federal-republic of Germany, Ozone Sci. Eng. 10 (1988) 393-403. doi:10.1080/01919518808552393.

[13] J. Lee, M.-J. Jun, M.-H. Lee, M.-H. Lee, S.-W. Eom, K.-D. Zoh, Production of various disinfection byproducts in indoor swimming pool waters treated with different disinfection methods., Int. J. Hyg. Environ. Health. 213 (2010) 465-74. doi:10.1016/j.ijheh.2010.09.005.

[14] D.J. Mah, H. Heacock, The Effectiveness of Ozone-chlorine Treatment for Reducing Chloramine Concentration Compared to Chlorine Treatment in Swimming Pools and Whirlpools, BCIT Environ. Heal. J. (2014). http://www.ncceh.ca/sites/default/files/BCIT-Mah-2014.pdf.

[15] S.J. Judd, G. Bullock, The fate of chlorine and organic materials in swimming pools, Chemosphere. 51 (2003) 869-879. ISI:000182637000007.

[16] H. Bader, J. Hoigné, Determination of ozone in water by the indigo method, Water Res. 15 (1981) 449-456. http://www.sciencedirect.com/science/article/pii/0043135481900543 (accessed January 14, 2014).

[17] U. Pinkernell, B. Nowack, H. Gallard, U. von Gunten, Methods for the photometric determination of reactive bromine and chlorine species with ABTS, Water Res. 34 (2000) 4343-4350. doi:10.1016/S0043-1354(00)00216-5.

[18] K.M.S. Hansen, R. Zortea, A. Piketty, S.R. Vega, H.R. Andersen, Photolytic removal of DBPs by medium pressure UV in swimming pool water., Sci. Total Environ. 443 (2013) 850-856. doi:10.1016/j.scitotenv.2012.11.064.

[19] C. Schmalz, F.H. Frimmel, C. Zwiener, Trichloramine in swimming pools - Formation and mass transfer, Water Res. 45 (2011) 2681-2690.

[20] A. Kanan, T. Karanfil, Formation of disinfection by-products in indoor swimming pool water: The contribution from filling water natural organic matter and swimmer body fluids, Water Res. 45 (2011) 926-932. ISI:000286790500052.

[21] K.M.S. Hansen, S. Willach, M.G. Antoniou, H. Mosbæk, H.-J. Albrechtsen, H.R. Andersen, Effect of $\mathrm{pH}$ on the formation of disinfection byproducts in swimming pool water - Is less THM better?, Water Res. 46 (2012) 6399-6409.

[22] K.M.S. Hansen, S. Willach, H. Mosbæk, H.R. Andersen, Particles in swimming pool filters - does pH determine the DBP formation?, Chemosphere. $87 \quad$ (2012) 241-247. doi:10.1016/j.chemosphere.2012.01.003.

[23] K.M.S. Hansen, H.-J. Albrechtsen, H.R. Andersen, Optimal pH in chlorinated swimming pools balancing formation of by-products., J. Water Health. 11 (2013) 465-472. doi:10.2166/wh.2013.156.

[24] I. Kristiana, A. Lethorn, C. Joll, A. Heitz, To add or not to add: The use of quenching agents for the analysis of disinfection by-products in water samples., Water Res. 59C (2014) 90-98. doi:10.1016/j.watres.2014.04.006.

[25] G. Hua, J. Kim, D. a. Reckhow, Disinfection byproduct formation from lignin precursors, Water Res. 63 (2014) 285-295. doi:10.1016/j.watres.2014.06.029.

[26] R.G. Rice, Chemistries of ozone for municipal pool and spa water treatment, J. Swim. Pool Spa Ind. 1 (1995) 25-44.

[27] N. Merlet, H. Thibaud, M. Dore, Chloropicrin formation during oxidative treatments in the preparation of drinking water, Sci. Total Environ. 47 (1985) 223-228. doi:0048-9697(85)90332-8 [pii].

[28] J. Hoigne, H. Bader, The Formation of Trichloronitromethane (Chloropicrin) and Chloroform in a Combined Ozonation/Chlorination Treatment of Drinking Water, Water Res. 22 (1988) 313-319. doi:10.1016/S0043-1354(88)90120-0. 